\title{
An empirical research of regional internal migration in Buryatia Republic based on environmental factors, as well as the information society readiness index factors
}

\author{
Oyuna Bazarova \\ East Siberia State University of Technology and \\ Management \\ Institute of Economics and Law \\ Ulan-Ude, Russia \\ Ouyna78@mail.ru
}

\author{
Galina Burtonova \\ East Siberia State University of Technology and \\ Management \\ Mechanical Engineering Faculty \\ Ulan-Ude, Russia
}

\author{
Irina Belomestnova \\ East Siberia State University of Technology and Management \\ Institute of Economics and Law \\ Ulan-Ude, Russia
}

\begin{abstract}
In this paper we analyze the specific features of regional migration. For such analysis we chose Buryat Republic. Our empirical research is based on gravity model. To perform econometric estimation we employ panel data estimation techniques. We provide random effect estimation techniques. This procedure is applied in Poisson pseudo maximum likelihood (PPML) estimation.

Our approach is innovative in the way that we include in econometric model not only general socio-economic determinants but environmental and information and telecommunication infrastructure development determinants as well. We also target our analysis on the one-way migration flow of home region. So, we are enabled to study the relationships in the gravity model in more specific way.
\end{abstract}

Keywords - migration, gravity model, Poisson pseudo maximum likelihood

\section{INTRODUCTION}

Migration is one of the most important socio-economic factors, which can reduce the interregional socio-economic differentiation. Migration affects the demographic structure of the population, determines the conditions of regional and local labor markets. The prognosis of the size and direction of migration flows can be the base of the successful socioeconomic policy. However, it is impossible without migration models development.

One of the specific features of the Russian economy is its regional differentiation that is rather high in comparison with the developed countries, but the level of internal migration flows is significantly low. For example, the internal migration in Russia was only $1.4 \%$ of the total population in the twothousand years. For comparison, the internal migration in the
United States on the average was $13.7 \%$ of the total population for the period 2000-2006, in Canada - 14.6\%, in Japan - $4.6 \%$ [1]. Among the main reasons for the low mobility of the Russian's population migration are the following: high costs of resettlement, underdevelopment of transportation network, limited market of housing rental, high cost of housing and rent, low income of the most people.

At the same time, in some Russian northern and eastern regions, there is a very high level of out-migration of the population. The main direction of the interregional internal migration in Russia is the movement from the East to the Center of Russia and to the Moscow region, which increases the imbalance in the distribution of the population on the territory of Russia.

Evaluation of migration flows in these regions is an important aspect of further socio-economic development of Russia. According to the State Migration Policy Concept of the Russian Federation for the period until 2025 (approved by the President of the Russian Federation of 13 June 2012), it is necessary to suspend the migration outflow from Siberia and the Far East until 2021, and provide the migratory influx of population to these areas until 2026.

However, to provide this process it is necessary to conduct a comprehensive assessment of the various factors that influence the migration processes in Russia.

In the economic literature, we can find different study of the influence of various factors on the interregional internal migration. Among the factors distinguish the socio-economic, socio-political, demographic, natural and geographical, ethnic and political, environmental factors. The degree of influence of these factors evaluated in the various econometric models 
developed for analysis of migration processes. At the same time, at present important factors for regional prosperity become the factors of information and telecommunication environment development and the information society readiness index as well. In this regard, in our view, these new factors reflect the degree of regional attractiveness and can be considered as an attraction factor of the migration.

The object of research is the internal interregional migration processes in Russia on the example Buryat Republic.

The empirical significance of the work lies in the field of calibration and testing of the econometric model for migration process. For empirical testing, we chose the gravity model for the one-way migration flow (i.e. migration flows between one home region and other regions).

We analyze panel data sets of interregional migration flows in Russia in time period 2001-2012. The analysis covers panel data sets of 78 regions of Russian Federation.

Defining Buryat Republic as a single "home region" i, the analysis is based on an econometric estimation of migration function from the home "region" to the other regions $\mathrm{j}$. Our data set consists of 924 observations of one-way migration flows in time period 12 years ( 1 X $77 \times 12)$.

Our approach is innovative in the way that we include in econometric model not only general socio-economic determinants but environmental and information and telecommunication infrastructure development determinants as well.

\section{Materials AND Methods (Model)}

The first mathematical model of migration was proposed by Young, 1924. He explored the rural migration to the United States and offered the first interactional pattern of migration (spatial interaction model) [2].

In the 40s of the XX century J. Zipf proposed gravity model of migration (Zipf, 1949): migration flows between regions is directly proportional to the population in the region and the region disposal arrival and inversely proportional to the square of the distance between the regions. This model has low explanatory power, as it considers only 3 factors. Furthermore, the distance is not very constant category for different regions of the country. Thus, it is appropriate to use a modified measure of the distance between the regions of the country [3].

Lee E. (1966) proposed the model of migration factors. In addition, this model is called extended gravity model [4].

The work of Andrienko and Guriev is interesting too, they tested the modified gravity model for Russia (Andrienko, Guriev, 2004). In particular, they proposed a model for panel data with individual fixed effect on the region to region data for the period 1992-1999. In 2006 they published a second paper, where they continued their previous work. They increased the sample of analyzing the interval from 1992 to 2003. As for the results, the authors again noted the applicability of the gravity model to the Russian data [5].
In general, many researchers consider that the gravity models for migration flows are consistent with the basic theoretical model. At the same time, it has some drawbacks for its use on the Russian's data.

Our empirical research is based on the so-called "gravitymodel", which often is used by some researchers of migration. This model is similar to the Newton's law of universal gravity. According to which "demographic" force of attraction between regions is directly proportional to the population in the region of origin and an arrival region and inversely proportional to the square of the distance between the regions.

$$
F_{i j}=\beta_{0} \frac{P_{i}^{\beta_{1}} p_{j}^{\beta_{2}}}{D_{i j}^{\beta_{3}}}
$$

Fij- the force of attraction between the regions $\mathrm{i}$ and $\mathrm{j}$; $\mathrm{Pi}$ the number of the population in given region; $\mathrm{Pj}-$ the number of the population in attraction region; Dij- the distance between the two regions.

Gravity model for migration considers the bilateral migration as the "gravity force" between two regions and suggests the same relationship between this force, masses of the regions proxies by the population and the distance between them.

For estimating purposes, the traditional gravity model of migration could be rewritten in the following form:

$F_{i j}=\beta_{0} P_{i}^{\beta_{1}} P_{j}^{\beta_{2}} D_{i j}^{\beta_{3}} \varepsilon_{i j}$,

Where $\varepsilon i j-$ the error term; $\beta 0, \beta 1, \beta 2, \beta 3$ are parameters to be estimated.

However, the recent studies of the estimation loglinearized version of the gravity model show its rather significant shortcomings; even if we use panel data for estimation. Namely, Santos Silva and Tenreyro (2006) show that the general approach cannot be used for zero force of attraction between the countries or regions. Moreover, they argued that estimating the log-linearized equation by OLS could lead to significant biases. Thus, the estimation based on the logarithmic transformed model creates a potential significant risk to the properly estimated coefficients.

In order to overcome log-linearized version of the gravity model shortcomings Santos Silva and Tenreyro (2006) suggested using Poisson pseudo maximum likelihood estimation (PPML) technique [6]. For our experiments, we use Poisson pseudo maximum likelihood (PPML) estimation.

In our research the following statistical information is used:

- regularly published data of Rosstat on social and economic processes in regions of Russia for the period 20012012;

- the matrixes of internal migration (so-called "shakhmatka") for the period 2001-2012. 
To assess the gravity model parameters is used the matrix of the shortest distances between regional centers of Russia. This calculation procedure was offered by Abramov A. (2000).

\section{RESULTS AND DISCUSSION}

In this paper we analyze the specific features of regional migration. For such analysis we chose Buryat Republic. Buryat Republic is the depressed region there is the constant migration outflow. In our opinion, such region accurately reflects the main problems of Russia in the field of migration.

The dynamic of migration outflow from Buryat Republic we show on the Exhibit 1. So, we can notice the constant growth of migration outflow from Buryat Republic. It was some decline in 2008-2009; we connect this process with world financial crises. However, in 2011 it was rapid growth which was continued in 2012.

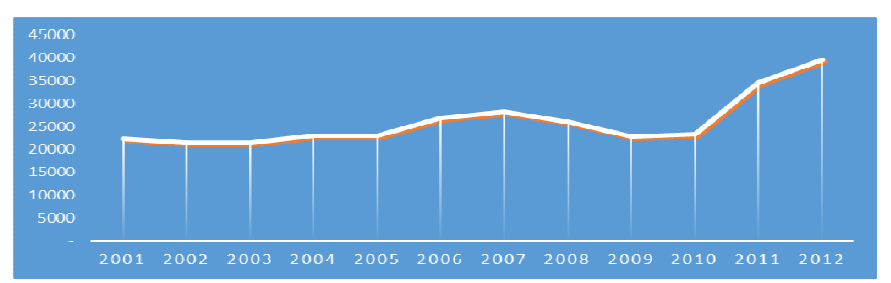

Exhibit 1 - Migration outflow from Buryat Republic

The structure of inter-regional migration is presented on the Exhibit 2. The population of the republic is mainly migrates within the Siberian FD. In the Siberian Federal District accounts for about $83 \%$ of the all emigration from the republic. The second place where the population migrates is the Central FD, is about $4.8 \%$ and the third is the Far East FD, the volume is about $4.5 \%$. So, population prefer to migrate on a short distance within the Federal District because of high level of the migrations' costs.

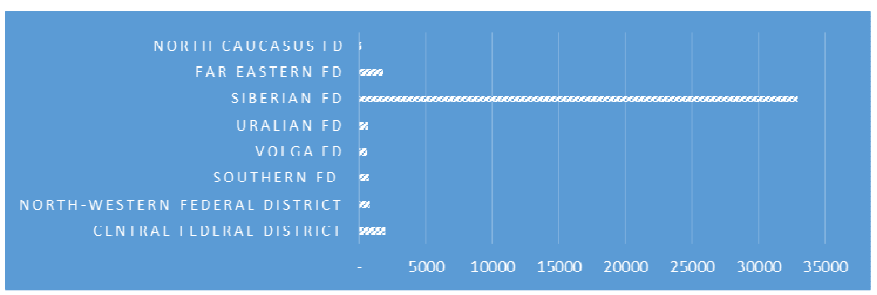

Exhibit 2 - The structure of inter-regional migration in Buryat Republic

In this section we also target our analysis on the one-way migration flow of home region. So, we are enabled to study the relationships in the gravity model in more specific way. Defining Buryat Republic as a single "home region" i, the analysis is based on an econometric estimation of migration function from the home "region" to the other regions $\mathrm{j}$.

The meaning of the variables is presented in Table 1of our report.
TABLE 1- Description of variables

\begin{tabular}{|c|c|c|}
\hline variables & description of variables & $\begin{array}{c}\text { the period } \\
\text { under } \\
\text { review }\end{array}$ \\
\hline \multicolumn{3}{|c|}{ Dependent variable: } \\
\hline $\mathrm{M}$ & $\begin{array}{l}\text { migration flow from the region } i \text { to } \\
\text { the region } j\end{array}$ & $2001-2012$ \\
\hline \multicolumn{3}{|c|}{ Independent variables: } \\
\hline \multicolumn{3}{|c|}{ Basic gravity model determinants } \\
\hline $\mathrm{D}$ & distance between two regions & \\
\hline $\mathrm{P}$ & $\begin{array}{l}\text { mid-year population in the region in } \\
\text { person }\end{array}$ & $2001-2012$ \\
\hline \multicolumn{3}{|c|}{ Socio-economic determinants (SEV) } \\
\hline $\mathrm{I}$ & average income per month in rubles & $2001-2012$ \\
\hline $\mathrm{U}$ & the average unemployment rate in\% & $2001-2012$ \\
\hline $\mathrm{Y}$ & $\begin{array}{l}\text { the gross regional product per } \\
\text { capita }\end{array}$ & $2001-2011$ \\
\hline ND & $\begin{array}{l}\text { the number of physicians per } \\
10,000 \text { population in human }\end{array}$ & $2001-2012$ \\
\hline \multicolumn{3}{|c|}{$\begin{array}{c}\text { Information and telecommunication infrastructure } \\
\text { determinants (ITV) }\end{array}$} \\
\hline NS & $\begin{array}{l}\text { the number of students at the } \\
\text { beginning of the school year to } \\
10,000 \text { inhabitants }\end{array}$ & $2001-2012$ \\
\hline $\mathrm{PC}$ & $\begin{array}{l}\text { Number of organizations used a PC } \\
(\%)\end{array}$ & $2001-2012$ \\
\hline $\mathrm{PE}$ & $\begin{array}{l}\text { Number of personal computers per } \\
100 \text { employees (pcs.) }\end{array}$ & $2001-2012$ \\
\hline IP & $\begin{array}{l}\text { Number of personal computers per } \\
100 \text { employees who have access to } \\
\text { the Internet (pcs.) }\end{array}$ & $2001-2012$ \\
\hline \multicolumn{3}{|c|}{ Environmental determinants (EV) } \\
\hline EA & $\begin{array}{l}\text { Emissions of air pollutants from } \\
\text { stationary sources (thous. Tons) }\end{array}$ & $2001-2012$ \\
\hline TW & $\begin{array}{l}\text { Average monthly temperature } \\
\left(\text { January }{ }^{\circ} \mathrm{C}\right)\end{array}$ & $2001-2012$ \\
\hline $\mathrm{TS}$ & $\begin{array}{l}\text { Average monthly temperature (July } \\
{ }^{\circ} \mathrm{C} \text { ) }\end{array}$ & $2001-2012$ \\
\hline
\end{tabular}

Descriptive statistic for the regions of Buryat Republic is as follows (Table 2). 
TABLE 2 -Descriptive statistics of Buryat Republic

\begin{tabular}{|c|c|c|c|c|c|}
\hline Variable & Obs & Mean & Std. Dev. & Min & Max \\
\hline M_ij & 924 & 134.6212 & 359.994 & 0 & 3834 \\
\hline$D_{-} i j$ & 924 & 4764.922 & 1532.203 & 454 & 6946 \\
\hline$I_{-} i$ & 924 & 8941.975 & 4983.472 & 2262.4 & 17119 \\
\hline$I_{-} j$ & 924 & 10470.62 & 8144.088 & 1141.2 & 110499.4 \\
\hline$U_{-} \dot{i}$ & 924 & 13.29167 & 3.000918 & 7.9 & 18.4 \\
\hline$U_{-j}$ & 924 & 8.213312 & 3.662641 & .8 & 29.3 \\
\hline$P_{-} i$ & 924 & 971.5 & 11.10781 & 960 & 997 \\
\hline$P_{-} j$ & 924 & 1831.026 & 1648.214 & 49 & 11613 \\
\hline 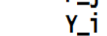 & 847 & 93537.73 & 41444.34 & 30315 & 159221 \\
\hline$Y_{-} j$ & 847 & 136591.9 & 139894 & 12562 & 1232269 \\
\hline ND_i & 924 & 39.9 & 1.579884 & 37.7 & 42.8 \\
\hline $\mathrm{ND}_{-} \mathrm{j}$ & 924 & 47.41948 & 10.86889 & 27 & 87.4 \\
\hline NS_j $\mathbf{i}$ & 924 & 39.71667 & 8.418517 & 26 & 48.9 \\
\hline NS_ $j$ & 924 & 86.78106 & 141.3784 & .1 & 1312.8 \\
\hline PC_ $\mathbf{i}$ & 924 & 9.25 & 6.04652 & 3 & 21 \\
\hline$P C_{-} j$ & 924 & 9.428571 & 7.089605 & 1 & 51 \\
\hline $\mathrm{PE}_{-} \mathrm{i}$ & 924 & 25.75 & 8.9782 & 15 & 41 \\
\hline$P E_{-} j$ & 924 & 25.8842 & 10.32487 & 6 & 72 \\
\hline IP_i & 924 & 96.95541 & 3.120853 & 89.7 & 100 \\
\hline IP_j & 924 & 94.8665 & 6.402288 & 60.41812 & 100 \\
\hline & 924 & 92.83333 & 6.404421 & 84 & 102 \\
\hline$E A-j$ & 924 & 254.9968 & 523.3535 & 1 & 4189 \\
\hline TW_i & 924 & -23.025 & 2.375145 & $-26 . \overline{5}$ & -17.8 \\
\hline$T W_{-} j$ & 924 & -11.51883 & 8.089918 & -36.8 & 4.9 \\
\hline TS_i & 924 & 17.29167 & .7312153 & 16.5 & 18.8 \\
\hline TS_j & 924 & 19.56645 & 3.379173 & 8.3 & 29.6 \\
\hline
\end{tabular}

We can say that the difference between the main variables are also very high. So, population may have a reason to migrate. The interpretation of the variables we give in previous section. In this case we provide only random effect estimation techniques. This procedure is applied in Poisson pseudo maximum likelihood (PPML) estimation. We perform RE model, because it was the only appropriate model as our assessments show. The resulting estimated of the model are summarized in the table 3 .

The model includes analysis of 77 pairs of regions. The dependent variable is the volume of migration. It is expressed in levels. The independent variables are used in logarithmic form. Zero migration flows observations represent about 2 percent of the sample.
TABLE 3 - Random effect model estimation for Buryat Republic

\begin{tabular}{|c|c|c|c|c|c|c|}
\hline $\begin{array}{l}\text { Randor-effects } \\
\text { Group variable: }\end{array}$ & $\begin{array}{l}\text { ?oisson reg } \\
\text { id }\end{array}$ & ssion & & $\begin{array}{l}\text { Number } \\
\text { Number }\end{array}$ & $\begin{array}{l}\text { f obs } \\
\text { f groups }\end{array}$ & $\begin{array}{r}844 \\
77\end{array}$ \\
\hline Randor effects & 1_i - Gamna & & & obs pe & group: $\begin{array}{r}\min = \\
\text { avg }= \\
\max =\end{array}$ & $\begin{array}{r}10 \\
11.0 \\
11\end{array}$ \\
\hline Log likelihood & $=-5607.99$ & & & $\begin{array}{l}\text { wald } \\
\text { Prob }\end{array}$ & (23) & $\begin{array}{r}2481.14 \\
0.0000\end{array}$ \\
\hline LLij & coef. & std Err. & $z$ & $P>|z|$ & [95\% conf. & . Interval] \\
\hline InP_i & 16.28381 & 2.044902 & 7.96 & 0.000 & 12.27588 & 20.29174 \\
\hline $7 n P_{-} \mathbf{j}$ & 1.32543 & .0880647 & & 0.000 & 1. 152876 & 1.498083 \\
\hline $\ln I_{-} i$ & -.9600706 & .1347187 & -7.13 & 0.000 & -1.224114 & -.6960268 \\
\hline $\ln I_{-} j$ & .4879387 & .0379955 & 12.84 & 0.000 & .4134688 & .5624086 \\
\hline $\ln U_{-i}$ & -.5495725 & .1137663 & -4.83 & 0.000 & -.7725502 & -.3265947 \\
\hline $\ln U_{-} \mathbf{j}$ & .0566531 & .023676 & 2.39 & 0.017 & .010249 & .1030572 \\
\hline $7 n Y_{-i}$ & 1.C69867 & .1574919 & 6.79 & 0.000 & .761189 & 1.378546 \\
\hline $1 n Y_{-} j$ & -.1880601 & .0434267 & -4.33 & 0.000 & -.2731748 & $-.1029<54$ \\
\hline TnND_i & 2.314135 & .6201094 & 3.73 & 0.000 & i. 058743 & 3.529527 \\
\hline InND_j & -.2532981 & .1141852 & -2.57 & 0.010 & -.517097 & -.0694991 \\
\hline Invs_j & -.4113005 & .0422748 & -9.73 & 0.000 & -.4941576 & $-.3284<34$ \\
\hline InNs_i & -.0662369 & .362792 & -0.18 & 0.855 & -.7772961 & .6448222 \\
\hline $7 n P C_{-j} j$ & -.1522647 & .0247665 & -6.15 & 0.000 & -.2008062 & -.1037232 \\
\hline InPC_i & -.1519033 & .1764335 & -0.86 & 0.389 & -.4977068 & .1939001 \\
\hline InPE_i & .2491846 & .3758296 & 0.66 & 0.507 & -.487428 & .9857972 \\
\hline $\operatorname{InPE}-j$ &.$(80583$ & .0500707 & 1.61 & 0.108 & -0175487 & .1787247 \\
\hline InIP_i & -.62762 & .4831892 & -1.30 & 0.194 & -1.574653 & .3194134 \\
\hline InIP-j & -.4280124 & .0598583 & -7.15 & 0.000 & -.5453324 & $=.3106924$ \\
\hline InEA $i$ & .2269355 & .212357 & 1.07 & 0.285 & -.1852765 & $.6431<75$ \\
\hline InEA-j & -.0762676 & .0279005 & -2.73 & 0.006 & $-.13 \operatorname{cs} 15$ & -.0215836 \\
\hline $\begin{array}{l}\text { Lnd_ij } \\
\text { InTw_i }\end{array}$ & $\begin{array}{l}-1.756075 \\
\text { (cmitted) }\end{array}$ & .1800109 & -9.76 & 0.000 & -2.10889 & -1.40326 \\
\hline $7 n T w_{-j}$ & .0164094 & .0101756 & 1.61 & 0.107 & -.0035343 & $.0363 \$ 31$ \\
\hline Tnts_i & $(\mathrm{cm}$ & & & & & \\
\hline InTS ${ }_{-j}$ & -.2309187 & .0414513 & -5.57 & 0.000 & -.3121618 & -.1496756 \\
\hline cons & -108.5211 & 14.65735 & & 0.000 & -137.249 & -79.79327 \\
\hline Analpha & $-.6 C 11498$ & .1554008 & & & -.9057299 & -.2965698 \\
\hline alpha & .548181 & .0851878 & & & .4042467 & .7433638 \\
\hline
\end{tabular}

Likelihood-ratio test of alpha $=0:$ chibar $z(01)=2.4 e+04$ Probs $=$ chibar $2=0.000$

We can say that we get not good result. Many coefficients of the variables are insignificant, as $p>0.05$. It concerns information and telecommunication infrastructure determinants and environmental one for given region (Buryat Republic).

However, Reset test show that model rather adequate. We get the following result $-\operatorname{chi} 2(1)=0.91 ;$ Prob $>$ chi $2=0.3397$.

\section{CONCLUSION}

Important result of the analysis is that the population in Russia migrates by small distances therefore the greatest percentage is the migration in the Federal district. In this connection it is possible to draw a conclusion that migration is limited to financial opportunities of the population and higher expenses, and risks when moving to more long distances. In general low migratory mobility of the population in Russia to long distances aggravates a demographic situation and doesn't promote development of market economy, interferes with fuller use of labor. Movements of the population within the Federal district eventually don't solve problems of social character.

Thus regions of the Far East for the analyzed period lost $10 \%$ of the population, and Siberia $-5,6 \%$ of the population. The analyzed period concerns quite perspective stage in development of the Russian economy.

In our paper we perform different models using Poisson pseudo maximum likelihood (PPML) estimation. 
The main estimation results are the following:

- except the basic gravity model determinants are rather significant number of physicians, gross regional product per capita, summer temperature, emission of air pollutants;

- direct relationship between emission of air pollutants parameter and migration flow, so in Russia migration depend on socio-economic situation in the region;

- the information and telecommunication infrastructure determinants have rather low impact. Moreover we get the opposite result, so our assumptions not confirmed. In our opinion, this result reflect not only the migrants' choice, but most likely depends on the quality of data in this sphere.

Thus, measures of migration policy of the Russian Federation have to be directed on the elimination of economic barriers of migration, i.e. on providing financial possibility of implementation of moving inhabitants, and also on the solution of the problem of migrants' arrangement and employment on a new place. Internal displacements of the population have to be carried out in those directions and in such scales which answer social and economic realities. Process of formation of the conditions influencing these processes generally lies out of the sphere of competence of migration policy. The existing realities are that both internal migrants and immigrants aspire to regions with higher standard of living, with good opportunities for employment and self-realization. The most attractive to them are large and the largest cities having the created work niches.

\section{Acknowledgment}

The authors are grateful to the Economics Education and Research Consortium, who provided financial support for research within the scientific project No. 14-044.

\section{References}

[1] Data from official statistical offices: Rosstat: http://gks.ru; Japan: http://www.e-stat.go.jp; USA: http://www.census.gov/; Canada: www.statcan.gc.ca.)

[2] Young E.C. The Movement of the Farm Population. Bulletin 426. Ithaca: New York Agricultural Experiment Station. 1924

[3] Zipf G.K. Human Behavior and the Principle of Least Effort. Addison-Wesley Press, Reading, Massachusetts, 1949.

[4] Lee E.S. A Theory of Migration // Demography, Vol. 3, No. 1. 1966. pp. 47-57.

[5] Andrienko Y., Guriev S. Determinants of interregional mobility in Russia. Evidence from panel data // Economics of Transition, 12(1). 2004. pp. 1-27.

[6] Silva, J. M. C. S. and S. Tenreyro The log of gravity // The Review of Economics and Statistics 88(4). 2006. pp. 641-658. 